\title{
Metastatic pancreatic cancer: Mechanisms and detection (Review)
}

\author{
XIANGLING CHEN ${ }^{1}$, FANGFANG LIU ${ }^{2}$, QINGPING XUE ${ }^{1}$, XIECHUAN WENG $^{3}$ and FAN XU ${ }^{1}$ \\ ${ }^{1}$ Department of Public Health, Chengdu Medical College, Chengdu, Sichuan 610500; \\ ${ }^{2}$ Department of Art, Art College, Southwest Minzu University, Chengdu, Sichuan 610041; \\ ${ }^{3}$ Department of Neuroscience, Beijing Institute of Basic Medical Sciences, Beijing 100850, P.R. China
}

Received June 17, 2021; Accepted August 19, 2021

DOI: $10.3892 /$ or.2021.8182

\begin{abstract}
Pancreatic cancer (PC) is a lethal malignancy. Its prevalence rate remains low but continues to grow each year. Among all stages of PC, metastatic PC is defined as late-stage (stage IV) PC and has an even higher fatality rate. Patients with PC do not have any specific clinical manifestations. Most cases are inoperable at the time-point of diagnosis. Prognosis is also poor even with curative-intent surgery. Complications during surgery, postoperative pancreatic fistula and recurrence with metastatic foci make the management of metastatic PC difficult. While extensive efforts were made to improve survival outcomes, further elucidation of the molecular mechanisms of metastasis poses a formidable challenge. The present review provided an overview of the mechanisms of metastatic PC, summarizing currently known signaling pathways (e.g. epithelial-mesenchymal transition, $\mathrm{NF}-\kappa \mathrm{B}$ and KRAS), imaging that may be utilized for early detection and biomarkers (e.g. carbohydrate antigen 19-9, prostate cancer-associated transcript-1, F-box/LRR-repeat protein 7 and tumor stroma), giving insight into promising therapeutic targets.
\end{abstract}

\section{Contents}

1. Introduction

2. Detection methods

3. Signaling pathways

4. Biomarkers

5. Conclusions

Correspondence to: Professor Xiechuan Weng, Department of Neuroscience, Beijing Institute of Basic Medical Sciences, Yard 27, Taiping Road, Haidian, Beijing 100850, P.R. China

E-mail: wengxc2000@sina.com

Professor Fan Xu, Department of Public Health, Chengdu Medical College, 783 Xindu Avenue, Chengdu, Sichuan 610500, P.R. China

E-mail:xufan@cmc.edu.cn

Key words: pancreatic cancer metastasis, mechanism, signaling pathway, biomarker

\section{Introduction}

Pancreatic cancer (PC) is the seventh leading cause of cancer-associated mortality worldwide (1) and it is predicted to become the second leading cause of cancer-related death in Western countries in the next decades (2). An up-to-date report estimated 57,600 new cases of PC in 2020. Among all cancer types, the 5-year survival rate is the lowest for all stages of cancers of the pancreas combined (9\%) (3). The 5 -year overall survival (OS) for metastatic PC is even poorer, namely as low as $2 \%(4,5)$, with a median survival expectancy of $<1$ year with current treatments (2). PC is hyperaggressive and evolves from non-invasive precursor lesions. Therefore, only minor symptoms may be noticed in the early stage. The lack of specific risk factors makes early detection a formidable challenge. The tumor grows along with genetic and epigenetic alterations. Delays in diagnosis lead to poor prognosis. Furthermore, no consensus has been reached regarding the optimal therapy. Focusing on early detection of metastatic $\mathrm{PC}$ at least prolongs the survival, improves life quality and reduces treatment-associated toxicities.

Metastatic PC is defined as stage IV cancer and it is not possible to completely remove it by surgery. Recent research has shifted the focus on prevention and early detection. However, effective and feasible screening strategies may provide accurate identification of at-risk individuals. Extensive studies have managed to determine signaling pathways, biomarkers or their combinations that may be accurate in detecting PC or predicting tumor metastasis $(4,5)$. The intricate communication among these elements and the low prevalence of PC make such attempts challenging.

\section{Detection methods}

Imaging modalities: CT and MRI. At diagnosis, it is common to detect that PC has already metastasized to a certain extent, so that curative surgery is impossible. Tumor cell migration has been a long-standing obstacle for disease management. At first, the tumor spreads confined to the pancreas. Subsequently, it spreads to adjacent organs, blood vessels that surround the pancreas or to other parts, but still within the abdomen. Much more aggressive types spread to distant organs such as the liver, lungs or bones (6). While it is rarely observed, it may also spread to the brain (7). Tumor cells travel to other body regions through the blood or lymphatic system. Therefore, the 
early identification of signs of such migration is paramount to the treatment course and improve OS outcomes. Accurate staging of $\mathrm{PC}$ is essential for the course of therapy. The diagnosis of PC is made based on pathological results that are combined with imaging. Commonly used imaging modalities for tumor assessment include computed tomography (8), magnetic resonance imaging (MRI), endoscopic ultrasound (EUS), positron emission tomography (PET) and magnetic resonance cholangiopancreatography. Furthermore, advanced techniques such as cinematic rendering and radiomics may be applied. Among all of those imaging techniques, CT and MRI are first-line diagnostic modalities for suspected PC. Both of them are capable of evaluating resectability. While most cases of PC have metastasis at the time-point of diagnosis, early detection of PC metastases via imaging features is still feasible.

CT is inarguably the optimal imaging modality in the initial assessment (9-11). CT uses X-rays to create a cross-section image of a region of the body. It accurately assesses metastatic spread or provides clues to treatment strategies for borderline resectable tumors (12). Rapid imaging with good spatial and temporal resolution makes $\mathrm{CT}$ a widely-used technique to assist diagnosis $(13,14)$. CT is preferred over MRI due to its lower cost and widespread availability (15). CT is also one of the two imaging modalities (another one is ultrasound) that is able to detect PC metastases (16). However, this is debatable. A study concluded that the performance of CT is poor in the diagnosis of small hepatic metastases (17). In addition, it is useful in quantifying changes in abdominal fat and lumbar muscle mass with the emergence of PC, thus helping with early detection $(18,19)$. A recent study determined that pretreatment CT quantitative imaging biomarkers from texture analysis and tumor size combined may predict survival outcomes compared with imaging biomarkers alone (20).

The use of CT has undergone a revolution. A large number of studies have applied different combinations of CT to determine whether this improves the accuracy and sensitivity. $\mathrm{PET} / \mathrm{CT}$ is an advanced technique. It provides 3-dimensional imaging based on the detection of radiation from the emission of positrons. PET/CT helps with observing molecular activities and is thus promising in the early detection of cancers and prediction of treatment response. It is inarguably of prognostic value in patients with $\mathrm{PC}$, regardless of metastases (21-23). A study evaluated the application of PET/CT for presurgical tumor staging of PC and concluded that its utility is rather limited (24). Hu et al (25) examined 19 patients with metastatic PC and determined that ${ }^{18} \mathrm{FDG}-\mathrm{PET} / \mathrm{CT}$ is useful in the early detection of metastases. A meta-analysis evaluated the sensitivity and accuracy of CT, ${ }^{18}$ FDG-PET and ${ }^{18}$ FDG-PET/CT, respectively, analyzing 11 eligible articles and 5 types of cancers (head and neck cancer, lung cancer, melanoma, sarcomas and colorectal cancer). The study determined that the integration of $\mathrm{CT}$ with PET performed best in assessing distant metastases (26). However, PC was not included in this analysis, possibly due to its low prevalence. It may be possible to perform another meta-analysis for PC metastases with the accumulation of cases in the near future. Furthermore, a slightly modified version of PET/CT, namely $\mathrm{PET} /$ contrast-enhanced (CE)-CT, was reported to have a diagnostic accuracy rate of $80 \%$ in the evaluation of staging in resectable PC, and surprisingly, it was as high as $94 \%$ for distant metastasis of PC, while it was low for lymph node (LN) metastasis (only 42\%) (27).

Multidetector CT is the most widely available and validated imaging modality for staging and diagnosis of PC (28). Thin-section arterial and venous phase imaging allows evaluation of distant metastases $(17,29)$ but requires a timely re-examination within a short period of time (30).

MRI, on the other hand, provided additional information on the stage or presence of small liver metastases that may otherwise be missed on CT. It is used when CT imaging lacks clarity or when CT is not applicable for patients. MRI has a slightly higher sensitivity compared with CT (83-94 vs. 76-96\%, respectively) (31-33). The reported accuracy in determining tumor resectability ranges from 73 to $87 \%$ for CT and from 70 to $80 \%$ for MRI (33). In terms of pancreatic surveillance for individuals at high risk, MRI is preferred due to its higher accuracy in detecting sub-centimeter pancreatic cysts and low ionizing radiation (34-36).

Mizumoto et al (37) retrospectively reviewed patients with PC. They indicated that iso- or hypo-attenuating regions were related to regional LN metastasis. Dilation of the main pancreatic duct and other non-enhancement features on preoperative MRI were reported to be helpful in predicting LN metastases. Leng et al (38) proposed the predictive value of $\mathrm{LN}$ metastases for postoperative recurrence in patients with invasive and noninvasive intraductal papillary mucinous neoplasms (IPMNs), suggesting that secondary signs of tumors may also be predictive factors. A retrospective study analyzed discriminatory signs on CT for patients with chronic calcifying pancreatitis and eventually developed PC. It was concluded that a hypodense mass at diagnosis is a predictive factor (39). As mentioned above, combinations of CT modalities have improved its efficacy to a large extent. Likewise, combining diffusion-weighted MRI with CE-MRI has nearly doubled the early detection of liver metastasis (from 156 to 397 cases) (40).

Machine learning, not surprisingly, paves a road for the automatic extraction of imaging features to classify and discriminate. Unsupervised training to 'read' scans effectively identifies foci that may otherwise be easily ignored or wrongly interpreted by radiologists. Automatic identification of the pancreas achieved high accuracy, with a reported Dice-Sørensen coefficient ranging from 71 to $82 \%$ with CT data $(41,42)$, and up to $83 \%$ with MR data $(43,44)$.

Apart from all of these merits mentioned above, a standardized reporting template for radiologists is required. Previously, the Society of Abdominal Radiology and the American Pancreatic Association adopted one template, emphasizing the importance of a complete, accurate and reproducible radiology report together with high-quality imaging. A repeat workup with tailored pancreas protocol multidetector CT angiography is beneficial for ruling out the possibility of a tumor (45). Whether early detection may achieve high accuracy and sensitivity through machine learning warrants evaluation of mass data and accurate algorithms. Furthermore, the smart utilization of imaging modalities to screen at-risk individuals should be promoted. A reported 3 and $20 \%$ of CT and MRI scans identified pancreatic cysts that are likely to develop into PC $(46,47)$, 
emphasizing the importance of a thorough interpretation of scanning images during screening.

Liquid biopsy. Tissue biopsy is the gold standard for the diagnosis of primary or metastatic diseases, but it is invasive. Liquid biopsy, a technique that has been used in lung cancer and breast cancer, is of high diagnostic value. Its clinical diagnostic value has now also been demonstrated for PC, including high-risk cohort surveillance, disease staging and longitudinal monitoring of tumor evolution and progression in response to treatment, as well as analyses to provide genomic and molecular information on potential pancreatic ductual adenocarcinoma (PDAC) (48). Liquid biopsies are minimally invasive and have an improved ability to represent tumor heterogeneity and nonsolid biological tissue, including circulating tumor cells (CTCs), primarily circulating tumor DNA (ctDNA) and exosomes secreted by cancer or normal cells, from all tumor sources, including metastatic sites (49).

CTCs are cells derived from primary and secondary tumors that may enter the vascular system at an early stage and seed to distant organs (50). The content is determined by enrichment and a combination of multiple detection methods (51). CTC has an important role in the transfer cascade reaction, but its limitations are low sensitivity, rarity and high heterogeneity (49). The number of CTCs may vary over time and space, with blood passing through the portal vein to the liver immediately after leaving the pancreas and large CTCs and clusters may become trapped. Furthermore, the blood flow in pancreatic malignancies is $60 \%$ less than that in normal pancreatic tissue, so that peripheral blood CTCs may not be the best choice for diagnosis and prognosis of $\mathrm{PC}$, but portal vein samples may be more representative of the CTC population (48). CTC detection tends to increase with tumor staging and is useful for the diagnosis of PC, but does not provide any relevant prognostic information (51).

ctDNA, also known as prenatal cell-free DNA, is the DNA released into the plasma by CTCs, the primary tumor or secondary tumor depositing necrotic or apoptotic cells as a result of cell death, but it is difficult to obtain effectively and is able to reflect the tumor load of patients with solid pancreatic tumor (49-51). The specificity of ctDNA was reported to be much higher than that of CTC and its sensitivity was slightly lower than that of CTC (49). CtDNA detection is based on KRAS mutations, but KRAS mutations are present not only in PDAC, but also in various other types of malignancies and even in chronic pancreatitis (CP) (50). Therefore, its relatively low specificity should be considered. The detection of ctDNA requires ultra-sensitive techniques and a large amount of plasma (12). At present, there is no reliable clinical evidence for its role in detecting early cancer.

Exosomes are small vesicles released from the plasma membrane by almost all cells, including cancer cells (50). Exosomes provide substrates for molecular profiling of circulating nucleic acids (such as exosomal DNA and exosomal RNA) and may also transfer a variety of biologically active molecules [such as proteins, lipids and pathogenic microRNAs (miRNAs/miRs) or mRNAs] from donor cells to recipient cells (48). Pancreatic cells have a strong exocrine function, leading to a high content of exosomes in peripheral blood with easy detection and high sensitivity (49). Since it enters the circulation at an early stage of cancer development, it may be used as a biomarker for early disease detection and tumor surveillance. Ariston Gabriel et al (52) illustrated that exosomes act as a carrier of miRNAs and other markers, including miR-196a, miR-1246, miR-191, miR-21, miR-451a, miR-16a and miR-196a, carbohydrate antigen 19-9 (CA19-9), miR-483-3p, miR-1246, miR-4644, miR-4525, miR-451a, miR-21, miR-155, miR196a, miR-1246, miR-4644, miR-3976, miR-4306, CD44v6, Tspan8, EpCAM, MET, CD104, exmiR-21, miR-17-5p, miR-10b, miR-550, miR-10b, miR-21, miR-30c and miR-181a, as well as low miR-let7a, which may be employed as diagnostic markers for PC.

The role of liquid biopsy in the early diagnosis of PDAC is theoretically promising as a standard of care for early diagnosis, molecular stratification, prognosis and predictive utility of PC, and for longitudinal monitoring of the effect of treatment of established disease (48). However, the data available so far appear contradictory and the true role of certain factors remains to be elucidated. One of the major limitations is the lack of standardized testing methods (50). Current technologies are frequently time-consuming, inherently limited in terms of processing and analysis, labor-intensive and potentially costly (48). Therefore, large-scale validation studies are required prior to clinical application (50).

Assay for transposase-accessible chromatin (ATAC)-array. ATAC sequencing (ATAC-seq) uses an overactive TN5 transposon to assess DNA accessibility, simultaneously cleaves DNA and inserts sequencing splices, preferentially in open chromatin regions. DNA sequencing libraries rich in DNA super-accessible regions are being generated and subjected to high-throughput sequencing. The readings are then aligned with the assembled genome to identify areas marked by high-density aligned reads. ATAC-seq, similar to other methods of chromatin accessibility analysis, provides a static assessment of the chromatin structure and reveals local and super-accessible regions. This method has proved to be valuable for high-throughput identification of active cis regulatory elements in a variety of cell types.

To simplify the assessment of chromatin accessibility signatures to the point of clinical utility, Dhara et al (53) developed a microarray approach termed 'ATAC-array', where the accessible regions from the differential chromatin accessibility signatures were arrayed on glass slides and then hybridized with fluorescent-labeled ATAC libraries. Applying this method to the original ATAC-seq library and the patient-derived organ-like independent library, they determined the characteristics of chromatin accessibility and transcription factors (TF), such as ZKSCAN1 and HNF1b, which are significantly related to the prognosis of PDAC, providing a novel chromatin-based prognostic paradigm for accurate oncological practice. The ATAC-array technique may be combined with nuclear localization of HNF1B by immunohistochemistry, which provides a simple and achievable prediction of the beneficial and detrimental epigenetic status of the disease for clinical work. However, whether poor patterns of chromatin accessibility contribute to the selection of patients with PDAC for epigenetic 'reprogramming' therapy remains to be determined. 


\section{Signaling pathways}

A deep understanding of the mechanisms of tumor metastases is paramount for disease management. Over the years, scientific researchers have made efforts to discover signaling pathways that may explain the pattern of metastasis during tumor progression. The goal itself is laudable but difficult to achieve and progress is slow. In the present review, it is not possible to cover all of the known signaling pathways. Instead, it was decided to focus on epithelial-mesenchymal transition (EMT), a mechanism that has received extensive attention from researchers, in addition to TANK binding kinase-1 (TBK1)-nuclear factor $\kappa \mathrm{B}(\mathrm{NF}-\mathrm{\kappa} \mathrm{B})$, an emerging signaling pathway that may be a potential therapeutic target candidate, as well as KRAS, as the major contributors of PC. Various relevant signaling pathways are illustrated in Fig. 1.

EMT. EMT is a physiological process that allows cancer cells to undergo morphological and genetic changes through epithelial-mesenchymal transformation, which underlies the highly metastatic function of cancer cells and contributes to their invasion and drug resistance. EMT is triggered by a variety of tumor microenvironmental factors, including cytokines, growth factors and chemotherapy drugs (54). EMT is a potential biomarker for early prognosis, so it is necessary to determine the effect of EMT on the metastatic process of cancer cells. Sannino et al (55) identified that BCL9L is a key modulator for invasion and metastasis of PC cells and reduced BCL9L expression delayed the response to TGF- $\beta$-induced EMT, which was associated with the loss of proliferation, migration and invasion of PC cells. In a study by Ye and Weinberg (56), TGF- $\beta$-induced E-cadherin expression in control Panc-1 cells was significantly downregulated and accompanied by the expression of mesenchymal genes (SNAI2, VIM) in PC cells, although not significantly. However, this EMT response was significantly reduced in cells that did not express the BCL9L gene $(55,57)$. When the expression level of E-cadherin increased, the expression level of the mesenchymal gene SNA12 decreased. Therefore, the expression of the BCL9L gene has a decisive role in inhibiting PC cells undergoing EMT in vivo and may effectively counteract PDAC invasion and metastasis by triggering EMT in addition to the classical WNT signaling pathway (55).

$T B K 1-N F-\kappa B$. The NF- $\kappa B$ family functions as regulators of cell proliferation, differentiation, immune responses, inflammation, invasion and metastasis. The activation of NF- $\mathrm{KB}$ is determined by proinflammatory cytokine paracrine loops $(58,59)$. Among those cytokines, IL-1 $\alpha$ was indicated to activate NF- $\kappa \mathrm{B}$ in metastatic PC cell lines, which in turn induced invasion mainly of the liver. NF- $\mathrm{KB}$ directly regulates EMT-TFs. In line with this, suppression of NF- $\kappa$ B by dehydroxymethylepoxyquinomicin degraded EMT-TF expression in PC (60). TBK1 modulates inflammatory signaling cascades and autophagy. Although the number of relevant studies is low, Labelle et al (61) reported that when NF- $\mathrm{BB}$ is activated synergistically by platelet-derived TGF- $\beta$ and direct platelet-tumor cell contact, it transforms the cells into an aggressive phenotype and enhances metastasis in vivo. Inhibiting the activation of NF- $\kappa \mathrm{B}$ and the expression of TGF- $\beta$ may effectively reduce tumor metastasis. Therefore, the metastasis of tumor cells is mainly through signals derived from platelets outside the tumor in vivo. However, this experiment was performed in mouse models of colon cancer and breast cancer and thus, numerous experiments are still required to verify this conclusion (Fig. 1).

$K R A S$. KRAS is one of the four major driver genes in PC. KRAS protein is a small GTPase per se. The functions of KRAS include endocytosis/exocytosis, survival, proliferation, invasion and transformation. When bound to GTP, KRAS is activated. KRAS protein interacts with $>80$ downstream effector proteins and signaling pathways, such as PI3K-AKT-mTOR, MAPK-MAPK kinase (MEK) or rapidly accelerated fibrosarcoma-MEK-ERK (51). Nuclear TFs are also activated (such as ELK, JUN and MYC), leading to stimulation of cell differentiation, proliferation, migration, transformation, adhesion and survival.

KRAS mutation is an early event in tumorigenesis. An activating point mutation of KRAS of oncogene on codon 12 (exon 2) is observed in the majority of PC cases. The existence of a KRAS mutation predicts poor prognosis in PDAC. Mutated KRAS contributes to tumor growth and metastasis in several ways. First, oncogenic KRAS secrete chemokines to activate $T$ cells, $B$ cells and macrophages, which drive the inflammatory response and tumor growth. Furthermore, the Warburg effect was observed during tumorigenesis, with an increase in glucose uptake and a shift from mitochondrial oxidative phosphorylation to aerobic glycolysis. Finally, high levels of lactate and reactive oxygen species are produced as a result of KRAS mutation (62).

Given that the oncogenic point mutation of KRAS is a frequent event during PDAC, the identification of this mutation in biological fluids and tumor tissues may prove useful in the diagnosis as well as in the prognostic evaluation and therapeutic decision-making. In the past 20 years, evaluation of KRAS mutation testing in patients with PDAC has been discussed in depth. A meta-analysis of mutated KRAS detection in pancreatic juice reported a pooled sensitivity of 59\% (95\% CI: 54-64\%) and a specificity of $87 \%$ (95\% CI: 84-89\%) (63). In addition to pancreatic juice, these studies have involved EUS-fine-needle aspiration samples and, more recently, circulating cell-free tumour DNA. The latter is part of the concept of liquid biopsy that also involves the search for CTCs, exosomes or miRNA. Various test methods are being performed on these samples to detect gene mutations, among which PCR is popular. However, the accuracy of PCR is challenged by poor specimens or complex cellular background. The adoption of digital PCR is complimentary, achieving high sensitivity in the presence of a noisy background (64).

\section{Biomarkers}

Despite extensive efforts to explore specific biomarkers of cancers, the origins of tumor metastasis have remained to be fully elucidated. It is hypothesized that the metastatic cascade results from an epigenetically altered transcriptional output of the oncogenic signals (65). While a vast number of hypotheses have been postulated, the present review focuses 


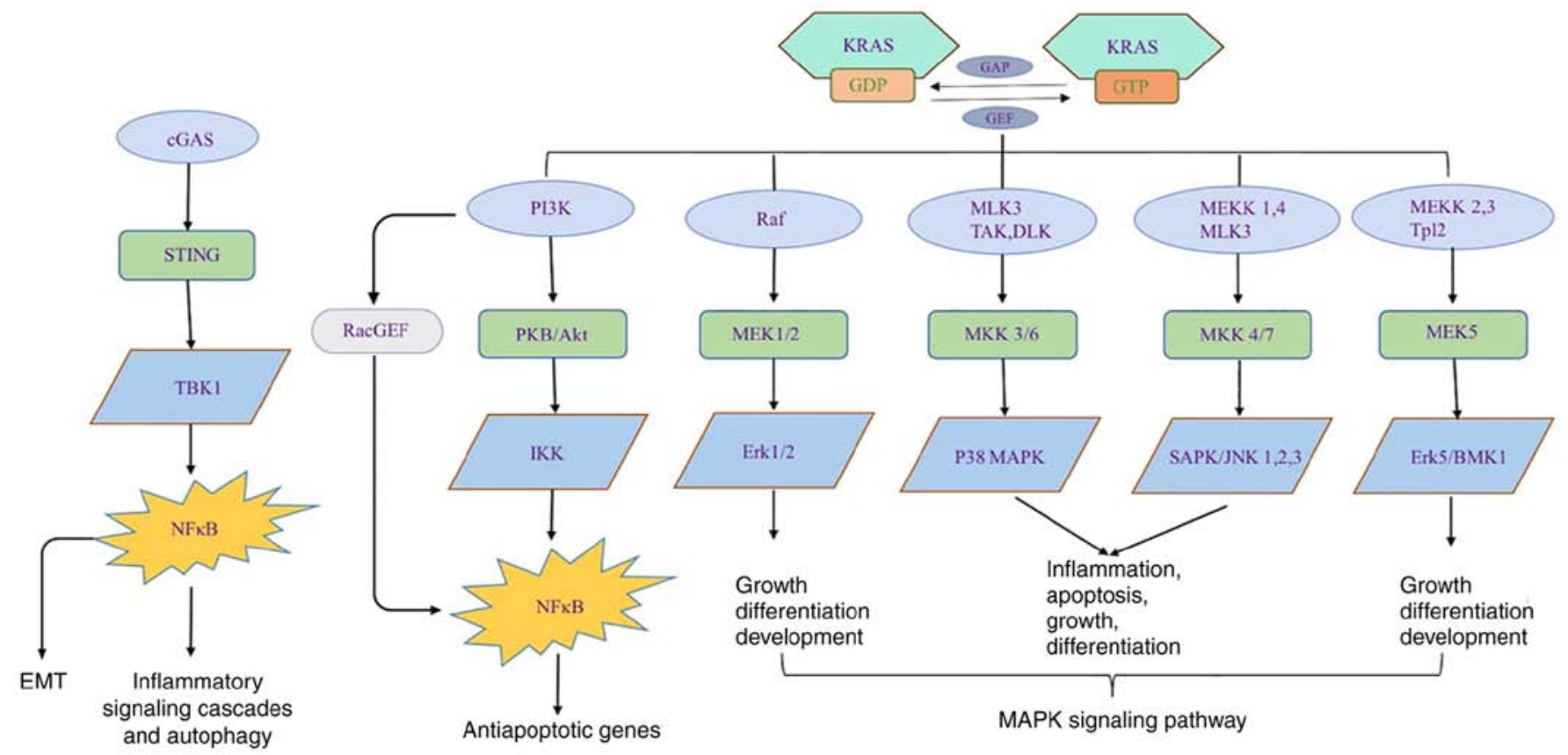

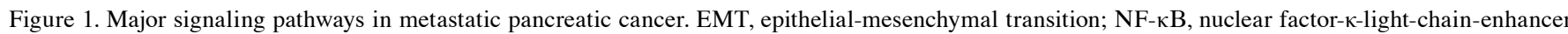
activated B cells; GDP, guanosine diphosphate; GTP, guanosine triphosphate; GAP, GTPase-activating protein; GEF, guanine nucleotide exchange factor; cGAS, cyclic GMP-AMP synthase; STING, stimulator of interferon genes; TBK1, TANK binding kinase-1; PI3K, phosphatidylinositol 3-kinase; IKK, inhibitor of NF-אB kinase; MEK, MAPK/ERK kinase; Erk, extracellular signal-regulated protein kinase; MLK3, mixed lineage kinase 3; TAK, transforming growth factor $\beta$-activated kinase; DLK, dual-leucine zipper kinase; P38 MAPK, P38 mitogen-activated protein kinase; MKK, MAP kinase kinase; SAPK/JNK, stress-activated protein kinase/c-Jun N-terminal kinase; MEKK, MEK kinase; BMK1, big MAP kinase 1.

on 7 biomarkers that were determined to regulate tumor cell migration in PC. These are neutrophil extracellular traps (NETs), prostate cancer-associated transcript-1 (PCAT-1), F-box/LRR-repeat protein 7 (FBXL7), CA19-9, pentraxin 3 (PTX3), tumor stroma and non-coding RNAs.

NETs. Since the discovery of NETs, their role has been widely debated. NETs have beneficial physiological consequences by strengthening the host defense. However, uncontrolled NETs are destructive and associated with cancer metastasis (66). Thus, the function of NETs in tumor progression may always heat a discussion. It was reported that chloroquine (67) represses NETs (67) and slows cancer progression (66). Murthy et al (68) further demonstrated the role of CQ in impeding NET formation. In their model, the severity of acute pancreatitis was decreased by CQ, thus improving survival by inhibiting NETs. In vivo culture of neutrophils performed by Hiroki et al (69) revealed that HMGB1 derived from NETs potentiates the degree of malignancy of cancer cells. Inhibition of HMGB1 by thrombomodulin inhibited NETs, hence impeding PC metastasis to the liver. However, the study of NETs is mostly performed using in vitro or murine models. Therefore, further investigations are required to determine whether these results are translatable to humans.

PCAT-1. Long noncoding RNAs (lncRNAs) are vital to tumor progression. Multiple lncRNAs have various pro-oncogenic functions in PC. For instance, HOTAIR, MALAT-1, ENST00000480739 and AFAP1-AS1 regulate cell invasion (70-73). The latter three lncRNAs are also promoters of cancer cell migration (74).
Using reverse transcription-quantitative PCR analysis, it was determined that upregulation of PCAT-1 inhibited the mRNA and protein expression of RBM5. In other words, knocking down PCAT-1 suppresses tumor cell migration and invasion (75). However, studies on PCAT-1 are currently scarce. Further investigation is required to fully explain the molecular mechanisms that drive tumor cell dissemination during cancer progression.

CA19-9. CA19-9 is a controversial biomarker. It lacks specificity in detecting PC. False-positive CA19-9 may be observed in obstructive jaundice even if successfully drained (76). Serum of patients that have biliary infection, inflammation or obstruction may test positive for CA19-9 $(77,78)$. It was indicated to be associated with lymph node metastasis and unfavorable survival outcome in patients with colon cancer (79).

In the American Association of Clinical Oncology guidelines, CA19-9 is not recommended as a substitute for imaging for post-operative evaluation (11). CA19-9 is not a robust screening tool for $\mathrm{PC}$ and previous studies reported a low positive predictive value ranging from 0.5 to $0.9 \%(80,81)$. However, it may be utilized for screening at-risk individuals (82). New international guidelines for managing populations at high risk for developing familial PC recommend that CA19-9 testing should be performed when suspected, regardless of its uncertain diagnostic value (83).

In fact, screening of at-risk individuals has gained interest from researchers recently. Extensive studies have identified risk factors for PC. A meta-analysis concluded that diabetes mellitus is both an early manifestation and consequence of PC with a summary relative risk of 1.94 (95\% CI, 1.66-2.27) (84). 
Long-standing pancreatitis is proclaimed to be a strong risk factor (85). Though rarely observed, PC may result from mucinous pancreatic cysts (IPMNs) and mucinous cystic neoplasms (86).

The diagnostic value of CA19-9 for PC has been argued to be satisfactory. According to a previous evaluation, multiple tumor markers did not perform better than the single use of CA19-9 (87). However, this requires further confirmation.

CA19-9 does provide useful hints regarding prognosis $(88,89)$. Certain studies concluded that CA19-9 was associated with poor survival outcome after pancreatic resection, with a cut-off value of $1,000 \mathrm{U} / \mathrm{ml}$ pre-operatively and $180 \mathrm{U} / \mathrm{ml}$ post-operatively $(90,91)$. It was proposed that CA 19-9 may be utilized to predict surgical recurrence. The use of CA19-9 has been suggested as an effective prognostic marker in conjunction with S100A4 (92).

Despite all the controversies, the present review favors the utilization of CA19-9 in the screening, diagnosis, prognosis and surveillance of PC. While there is currently no consensus regarding the cut-off value of CA19-9 during these steps, nor any clear understanding of the relationship between CA19-9 and PC, it is likely to be beneficial to monitor CA19-9 together with other approaches.

FBXL7. The SCF E3 ubiquitin ligase family controls abundant protein degradation through the proteasome system and is pivotal in tumorigenesis and progression. However, the knowledge regarding their role in PC metastasis remains limited. Low FBXL7 mRNA and protein levels were observed in PC metastasis. Defects in the FBXL7-mediated degradation of $\mathrm{c}-\mathrm{SRC}$ increase cell migration and invasion and the expression of EMT markers (93). Insignificant FBXL7 expression predicts poor survival. Previous work unveiled the anti-metastatic role of ubiquitin ligase subunit FBXL7 in pancreatic carcinoma using decitabine (a Food and Drug Association-approved DNA-methylase inhibitor to reduce metastasis) (94). FBXL7 promotes cancer cell invasion and metastasis through regulation of EMT, while EMT may be mediated by c-SRC. In numerous types of solid tumor, c-SRC expression levels are rather high and correlated with metastasis. FBXL7 was observed to coordinate c-SRC degradation and to further suppress the reduced EMT and tumor cell migration (93). Collectively, FBXL7 may be a candidate target for PC therapy.

PTX3. PTX3 belongs to the pentachlorobenzene toxin family and is synthesized in numerous cell types, such as endothelial cells, macrophages and monocytes. It has been reported that serum PTX3 is an important and specific biomarker for early infection (95). It helps with the diagnosis of PDAC and distinguish it from non-cancerous conditions such as intraductal papillary mucinous tumors or chronic pancreatitis (CP). PTX3 levels in blood samples from patients with PDAC, healthy volunteers and subjects with other non-cancerous diseases of the pancreas were measured by ELISA and patients with PDAC had significantly higher serum levels of PTX3 than patients with intraductal papillary myxoma or $\mathrm{CP}$, and the sensitivity and specificity of PTX3 in detecting PDAC were better than those of serum CA19-9 and carcinoembryonic antigen. Goulart et al (96) advocated that PTX3 is a putative stromal-derived biomarker for PDAC, which warrants further testing in larger, prospective, multi-center cohorts and within clinical trials targeting stroma.

Tumor stroma. A dense stroma that blocks therapeutic agents is a typical hallmark of PC and this subsequently facilitates chemoresistance. Stroma depletion is an option to enhance therapeutic effects, which, in turn, hinders the stroma's role in tumor metastasis. Thus, it has been proposed to reshape tumor stroma to alter the communication between cancer cells and stromal compartments, eventually improving survival outcomes. Stromal-based therapies heavily rely on multiple elements of stroma, such as the extracellular matrix (ECM), immune cells, carcinoma-associated fibroblasts, blood and the lymphatic vasculature. It was argued that effects of ECM remodeling are not as promising as expected due to the heterogeneity of the tumor microenvironment (97). However, ECM alterations induce changes in the intra-tumor vasculature (98). In other words, such intricate interaction makes manipulation even better. Changes in either of them may affect stromal performance during cancerous progression and alter the outcome of malignancy. Theoretically, stroma depletion is a promising potential means of PC treatment. However, several clinical studies indicated that the combination of stromal depletion and chemotherapy was not beneficial (99-103). Of note, several studies using mouse models of PC exhibited undesired adverse effects, including cachexia, weight loss, hypoxia, increased immunosuppression and vascular density, loss of vascular integrity, an enhanced cancer stem cell-like phenotype and acidosis (103-106). To conclude, the stromal alteration strategy enhances the efficacy of therapeutic agent delivery but prior to its implementation, suppression of its side effects must be achieved first.

Non-coding RNAs. Non-coding RNAs are RNA molecules that are transcribed from genomes that do not code for proteins. They may be divided into two categories. In the first category, the role of the non-coding RNAs is to ensure that the basic biological functions are being performed and they are called constitutive noncoding RNAs. The other category is that of the macro-control noncoding RNAs (regulatory non-coding RNAs). Non-coding RNA participates in processes of various cellular functions, such as EMT, cell cycle control, apoptosis and autophagy (107).

miRNAs as a class of small non-coding RNAs regulate gene expression at the post-transcriptional level by binding to the 3'untranslated region of their target mRNAs. Altered expression of miRNAs has been indicated to be involved in the regulation of crucial pathological processes in tumorigenesis, progression and metastasis of PC (Table I). As a potential non-invasive biomarker for numerous cancer types, miRNA may be used as a diagnostic and prognostic marker for PC $(108,109)$. Khan et al (110) demonstrated a significant upregulation of miR-215-5p, miR-122-5p and miR-192-5p, while the levels of miR-30b-5p and miR-320b were significantly lower in serum samples from patients with PDAC as compared to those from subjects with $\mathrm{CP}$ and healthy controls (HC). Receiver operating characteristic analysis indicated that these 5 miRNAs are able to distinguish PDAC from both $\mathrm{CP}$ and $\mathrm{HC}$. Hence, this panel may serve as a non-invasive biomarker for the early detection of PDAC.

miRNAs may also be used as prognostic biomarkers. It was reported that high expression of miR-212 and miR-675 and low expression of miR-148a, miR-187 and let-7g in 
Table I. Biomarkers for metastatic PC.

\begin{tabular}{|c|c|c|}
\hline Noncoding RNAs & Biological function & (Refs.) \\
\hline $\operatorname{miR}-21$ & $\begin{array}{l}\text { Interferes with the expression of key self-renewal regulators (such as Oct } 4 \text {, Nanog and } \\
\text { Sox2), degrades maternally inherited mRNA, initiates or promotes EMT, increases proliferation, } \\
\text { invasion and chemoresistance }\end{array}$ & (114) \\
\hline $\operatorname{miR}-24$ & Promotes cell proliferation and blood vessel formation, inhibits PANC1 cell apoptosis & $(115)$ \\
\hline miR-155 & Promotes cell proliferation and tumorigenesis & $(116,117)$ \\
\hline $\operatorname{miR}-221 / 222$ & Promotes cell proliferation & $(116)$ \\
\hline $\operatorname{miR}-210$ & Inhibits tumor growth & $(118)$ \\
\hline $\operatorname{miR}-155$ & Promotes cell proliferation, inhibits apoptosis & $(119)$ \\
\hline miR-200b & Inhibits EMT and cancer cell migration & $(120)$ \\
\hline miR-196a-2/196 & Promotes cell proliferation and inhibits cell apoptosis & $(121)$ \\
\hline $\operatorname{miR}-27 \mathrm{a}$ & Regulates tumor growth, colonization and migration & $(122)$ \\
\hline $\operatorname{miR}-506$ & Inhibits tumorigenesis & $(123)$ \\
\hline $\operatorname{miR}-301 \mathrm{a}$ & Promotes the proliferation of PC cells and inhibits their protein expression in vitro and in vivo & $(124)$ \\
\hline $\operatorname{miR}-98-5 p$ & Promotes the proliferation and metastasis of PC cells & $(125)$ \\
\hline $\operatorname{miR}-377$ & Inhibits the growth and migration of pancreatic tumors and induces apoptosis & $(126)$ \\
\hline $\operatorname{miR}-135 \mathrm{a}$ & Inhibits cell proliferation & $(8)$ \\
\hline $\operatorname{miR}-203-3 p$ & $\begin{array}{l}\text { Inhibits the expression of fibroblast growth factor } 2 \text {; regulates the proliferation, invasion and } \\
\text { migration of PC cells }\end{array}$ & $(127)$ \\
\hline $\operatorname{miR}-125 a-3 p$ & Suppresses EMT & $(128)$ \\
\hline
\end{tabular}

PC, pancreatic cancer; miR, microRNA; EMT, epithelial-mesenchymal transition.

non-microanatomical carcinoma tissues from patients undergoing PC surgery was able to predict OS, and high expression of miR-155, miR-155, miR-203, miR-210 and miR-222 in pancreatic tumors was associated with a low survival rate $(111,112)$. Furthermore, low expression of miR-7 was reported to be associated with poor prognosis and to accelerate tumor progression in PC (113).

\section{Conclusion}

The goal of early detection of metastatic PC is laudable. Obstacles are the relatively low prevalence of PC (and even smaller subpopulations), resulting in a less feasible screening protocol for the general population. Biomarkers for early detection remain to be validated. Unveiling the roles of signaling pathways in PC may be insufficient for the timely diagnosis of PC. Novel combinations with imaging modalities with state-of-the-art robust algorithms may clearly determine the anatomical structure and pathological changes for this disease.

\section{Acknowledgements}

Not applicable.

\section{Funding}

This work was supported by the National Natural Science Foundation of China (grant no. 82073833), Chengdu Science and Technology Bureau focus on research and development support plan (grant no. 2019-YF09-00097-SN), the popular scientific research project of Sichuan Health Commission (grant no. 20PJ171) and Yunnan education program (grant no. SYSX202036).

\section{Availability of data and materials}

Data sharing is not applicable.

\section{Authors' contributions}

$\mathrm{XC}$ and FX drafted the manuscript, FL drew the figure, and QX and XW collected the references and extracted the necessary data. All authors read and approved the final manuscript. Data authentication is not applicable.

\section{Ethics approval and consent to participate}

Not applicable.

\section{Patient consent for publication}

Not applicable.

\section{Competing interests}

The authors declare that they have no competing interests.

\section{References}

1. Rawla P, Sunkara T and Gaduputi V: Epidemiology of pancreatic cancer: Global trends, etiology and risk factors. World J Oncol 10: 10-27, 2019. 
2. Neoptolemos JP, Kleeff J, Michl P, Costello E, Greenhalf W and Palmer DH: Therapeutic developments in pancreatic cancer: Current and future perspectives. Nat Rev Gastroenterol Hepatol 15: 333-348, 2018.

3. Siegel RL, Miller KD and Jemal A: Cancer statistics, 2020. CA Cancer J Clin 70: 7-30, 2020

4. Jemal A, Siegel R, Ward E, Murray T, Xu J, Smigal C and Thun MJ: Cancer Statistics, 2006. CA Cancer J Clin 56: 106-130, 2006.

5. Malvezzi M, Bertuccio P, Levi F, La Vecchia C and Negri E: European cancer mortality predictions for the year 2013. Ann Oncol 24: 792-800, 2013.

6. Yang W, Zhang J, Wang H, Gao P, Singh M, Shen K and Fang N: Angiotensin II downregulates catalase expression and activity in vascular adventitial fibroblasts through an AT1R/ERK1/2-dependent pathway. Mol Cell Biochem 358 21-29, 2011

7. Sasaki T, Sato T, Nakai Y, Sasahira N, Isayama H and Koike K: Brain metastasis in pancreatic cancer: Two case reports. Medicine (Baltimore) 98: e14227, 2019.

8. Dang Z, Xu WH, Lu P, Wu N, Liu J, Ruan B, Zhou L, Song WJ and Dou KF: MicroRNA-135a inhibits cell proliferation by targeting Bmil in pancreatic ductal adenocarcinoma. Int J Biol Sci 10: 733-745, 2014

9. Tempero MA, Malafa MP, Al-Hawary M, Asbun H, Bain A, Behrman SW, Benson AB III, Binder E, Cardin DB, Cha C, et al: Pancreatic adenocarcinoma, version 2.2017, NCCN Clinical Practice Guidelines in Oncology. J Natl Compr Canc Netw 15: 1028-1061, 2017

10. Tempero MA Malafa MP, Chiorean EG, Czito B, Scaife C, Narang AK, Fountzilas C, Wolpin BM, Al-Hawary M, Asbun H, et al: Pancreatic adenocarcinoma, version 1.2019. J Natl Compr Canc Netw 17: 202-210, 2019.

11. Sohal DPS, Kennedy EB, Cinar P, Conroy T, Copur MS, Crane CH, Garrido-Laguna I, Lau MW, Johnson T, Krishnamurthi S, et al: Metastatic pancreatic cancer: ASCO Guideline Update. J Clin Oncol: Aug 5, 2020 (Epub ahead of print). doi: 10.1200/JCO.20.01364.

12. Mellby LD, Nyberg AP, Johansen JS, Wingren C, Nordestgaard BG, Bojesen SE, Mitchell BL, Sheppard BC, Sears RC and Borrebaeck CA: Serum biomarker signature-based liquid biopsy for diagnosis of early-stage pancreatic cancer. J Clin Oncol 36: 2887-2894, 2018

13. Lee ES and Lee JM: Imaging diagnosis of pancreatic cancer: A state-of-the-art review. World J Gastroenterol 20: 7864-7877, 2014.

14. Singhi AD, Koay EJ, Chari ST and Maitra A: Early detection of pancreatic cancer: Opportunities and challenges. Gastroenterology 156: 2024-2040, 2019.

15. Garces-Descovich A, Beker K, Jaramillo-Cardoso A, James Moser A and Mortele KJ: Applicability of current NCCN Guidelines for pancreatic adenocarcinoma resectability: Analysis and pitfalls. Abdom Radiol (NY) 43: 314-322, 2018.

16. Zins M, Matos $C$ and Cassinotto $C$ : Pancreatic adenocarcinoma staging in the Era of preoperative chemotherapy and radiation therapy. Radiology 287: 374-390, 2018.

17. Wong JC and Lu DS: Staging of pancreatic adenocarcinoma by imaging studies. Clin Gastroenterol Hepatol 6: 1301-1308, 2008.

18. Sah RP, Sharma A, Nagpal S, Patlolla SH, Sharma A, Kandlakunta H, Anani V, Angom RS, Kamboj AK, Ahmed N, et al: Phases of metabolic and soft tissue changes in months preceding a diagnosis of pancreatic ductal adenocarcinoma. Gastroenterology 156: 1742-1752, 2019.

19. Danai LV, Babic A, Rosenthal MH, Dennstedt EA, Muir A, Lien EC, Mayers JR, Tai K, Lau AN, Jones-Sali P, et al: Altered exocrine function can drive adipose wasting in early pancreatic cancer. Nature 558: 600-604, 2018.

20. Cheng SH, Cheng YJ, Jin ZY and Xue HD: Unresectable pancreatic ductal adenocarcinoma: Role of CT quantitative imaging biomarkers for predicting outcomes of patients treated with chemotherapy. Eur J Radiol 113: 188-197, 2019.

21. Mohamed E, Needham A, Psarelli E, Carroll M, Vinjamuri S Sanghera B, Wong WL, Halloran C and Ghaneh P: Prognostic value of (18)FDG PET/CT volumetric parameters in the survival prediction of patients with pancreatic cancer. Eur J Surg Oncol 46: 1532-1538, 2020.

22. Im HJ, Oo S, Jung W, Jang JY, Kim SW, Cheon GJ, Kang KW, Chung JK, Kim EE and Lee DS: Prognostic value of metabolic and volumetric parameters of preoperative FDG-PET/CT in patients with resectable pancreatic cancer. Medicine (Baltimore) 95: e3686, 2016.
23. Zhu D, Wang L, Zhang H, Chen J, Wang Y, Byanju S and Liao M: Prognostic value of $18 \mathrm{~F}-\mathrm{FDG}-\mathrm{PET} / \mathrm{CT}$ parameters in patients with pancreatic carcinoma: A systematic review and meta-analysis. Medicine (Baltimore) 96: e7813, 2017.

24. Kim MJ, Lee KH, Lee KT, Lee JK, Ku BH, Oh CR, Heo JS, Choi SH and Choi DW: The value of positron emission tomography/computed tomography for evaluating metastatic disease in patients with pancreatic cancer. Pancreas 41: 897-903, 2012.

25. Hu S, Zhang J, Zuo C, Cheng C, Liu Q and Sun G: (18)F-FDGPET/CT findings in pancreatic metastasis. Radiol Med 120: $887-898,2015$

26. Gao G, Gong B and Shen W: Meta-analysis of the additional value of integrated 18FDG PET-CT for tumor distant metastasis staging: Comparison with 18FDG PET alone and CT alone. Surg Oncol 22: 195-200, 2013.

27. Asagi A, Ohta K, Nasu J, Tanada M, Nadano S, Nishimura R, Teramoto N, Yamamoto K, Inoue T and Iguchi H: Utility of contrast-enhanced FDG-PET/CT in the clinical management of pancreatic cancer: Impact on diagnosis, staging, evaluation of treatment response, and detection of recurrence. Pancreas 42: 11-19, 2013.

28. Callery MP, Chang KJ, Fishman EK, Talamonti MS, William Traverso L and Linehan DC: Pretreatment assessment of resectable and borderline resectable pancreatic cancer: Expert consensus statement. Ann Surg Oncol 16: 1727-1733, 2009.

29. Bae JS, Kim JH, Joo I, Chang W and Han JK: MDCT findings predicting post-operative residual tumor and survival in patients with pancreatic cancer. Eur Radiol 29: 3714-3724, 2019.

30. Raman SP, Reddy S, Weiss MJ, Manos LL, Cameron JL, Zheng L, Herman JM, Hruban RH, Fishman EK and Wolfgang CL: Impact of the time interval between MDCT imaging and surgery on the accuracy of identifying metastatic disease in patients with pancreatic cancer. AJR Am J Roentgenol 204: W37-W42, 2015.

31. Ichikawa T, Haradome H, Hachiya J, Nitatori T, Ohtomo K, Kinoshita T and Araki T: Pancreatic ductal adenocarcinoma: Preoperative assessment with helical CT versus dynamic MR imaging. Radiology 202: 655-662, 1997.

32. Chen FM, Ni JM,Zhang ZY,Zhang L, Li B and Jiang CJ: Presurgical evaluation of pancreatic cancer: A comprehensive imaging comparison of CT versus MRI. Am J Roentgenol 206: 526-535, 2016.

33. Sheridan MB, Ward J, Guthrie JA, Spencer JA, Craven CM, Wilson D, Guillou PJ and Robinson PJ: Dynamic contrast-enhanced MR imaging and dual-phase helical CT in the preoperative assessment of suspected pancreatic cancer: A comparative study with receiver operating characteristic analysis. AJR Am J Roentgenol 173: 583-590, 1999.

34. Canto MI, Harinck F, Hruban RH, Offerhaus GJ, Poley JW, Kamel I, Nio Y, Schulick RS, Bassi C, Kluijt I, et al: International Cancer of the Pancreas Screening (CAPS) Consortium summit on the management of patients with increased risk for familial pancreatic cancer. Gut 62: 339-347, 2013.

35. Pereira SP, Oldfield L, Ney A, Hart PA, Keane MG, Pandol SJ, Li D, Greenhalf W, Jeon CY, Koay EJ, et al: Early detection of pancreatic cancer. Lancet Gastroenterol Hepatol 5: 698-710, 2020.

36. Canto MI, Hruban RH, Fishman EK, Kamel IR, Schulick R, Zhang Z, Topazian M, Takahashi N, Fletcher J, Petersen G, et al: Frequent detection of pancreatic lesions in asymptomatic high-risk individuals. Gastroenterology 142: 796-804, 2012.

37. Mizumoto $\mathrm{T}$, Toyama $\mathrm{H}$, Terai S, Mukubou $\mathrm{H}$, Yamashita $\mathrm{H}$, Shirakawa S, Nanno Y, Sofue K, Kido M, Ajiki T and Fukumoto T: Prediction of lymph node metastasis in pancreatic neuroendocrine tumors by contrast enhancement characteristics. Pancreatology 17: 956-961, 2017.

38. Leng KM, Wang ZD, Zhao JB, Cui YF and Zhong XY: Impact of pancreatic margin status and lymph node metastases on recurrence after resection for invasive and noninvasive intraductal papillary mucinous neoplasms of the pancreas: A meta-analysis. Dig Surg 29: 213-225, 2012.

39. Mohamed A, Ayav A, Belle A, Orry X, Chevaux JB and Laurent V: Pancreatic cancer in patients with chronic calcifying pancreatitis: Computed tomography findings-a retrospective analysis of 48 patients. Eur J Radiol 86: 206-212, 2017.

40. Riviere DM, van Geenen EJM, van der Kolk BM, Nagtegaal ID, Radema SA, van Laarhoven CJHM and Hermans JJ: Improving preoperative detection of synchronous liver metastases in pancreatic cancer with combined contrast-enhanced and diffusion-weighted MRI. Abdom Radiol (NY) 44: 1756-1765, 2019.

41. Farag A, Le Lu, Roth HR, Liu J, Turkbey E and Summers RM: A Bottom-up approach for pancreas segmentation using cascaded superpixels and (Deep) image patch labeling. IEEE Trans Image Process 26: 386-399, 2017. 
42. Karasawa K, Oda M, Kitasaka T, Misawa K, Fujiwara M, Chu C, Zheng G, Rueckert D and Mori K: Multi-atlas pancreas segmentation: Atlas selection based on vessel structure. Med Image Anal 39: 18-28, 2017

43. Gou S, Lee P, Hu P, Rwigema JC and Sheng K: Feasibility of automated 3-dimensional magnetic resonance imaging pancreas segmentation. Adv Radiat Oncol 1: 182-193, 2016.

44. Chu LC, Goggins MG and Fishman EK: Diagnosis and detection of pancreatic cancer. Cancer J 23: 333-342, 2017.

45. Al-Hawary MM, Francis IR, Chari ST, Fishman EK, Hough DM, Lu DS, Macari M, Megibow AJ, Miller FH, Mortele KJ, et al: Pancreatic ductal adenocarcinoma radiology reporting template: Consensus statement of the society of abdominal radiology and the american pancreatic association. Gastroenterology 146: 291-304.e1, 2014

46. Laffan TA, Horton KM, Klein AP, Berlanstein B, Siegelman SS Kawamoto S, Johnson PT, Fishman EK and Hruban RH: Prevalence of unsuspected pancreatic cysts on MDCT. AJR Am J Roentgenol 191: 802-807, 2008.

47. Lee KS, Sekhar A, Rofsky NM and Pedrosa I: Prevalence of incidental pancreatic cysts in the adult population on MR imaging. Am J Gastroenterol 105: 2079-2084, 2010.

48. Zhu Y, Zhang H, Chen N, Hao J, Jin H and Ma X: Diagnostic value of various liquid biopsy methods for pancreatic cancer: A systematic review and meta-analysis. Medicine (Baltimore) 99: e18581, 2020

49. Kamyabi N, Bernard V and Maitra A: Liquid biopsies in pancreatic cancer. Expert Rev Anticancer Ther 19: 869-878, 2019.

50. Kunovsky L, Tesarikova P, Kala Z, Kroupa R, Kysela P, Dolina J and Trna J: The use of biomarkers in early diagnostics of pancreatic cancer. Can J Gastroenterol Hepatol 2018: 5389820, 2018

51. Sefrioui D, Blanchard F, Toure E, Basile P, Beaussire L, Dolfus C Perdrix A, Paresy M, Antonietti M, Iwanicki-Caron I, et al: Diagnostic value of CA19.9, circulating tumour DNA and circulating tumour cells in patients with solid pancreatic tumours. $\mathrm{Br}$ J Cancer 117: 1017-1025, 2017

52. Ariston Gabriel AN, Wang F, Jiao Q, Yvette U, Yang X, Al-Ameri SA, Du L, Wang YS and Wang C: The involvement of exosomes in the diagnosis and treatment of pancreatic cancer. Mol Cancer 19: 132, 2020.

53. Dhara S, Chhangawala S, Chintalapudi H, Askan G, Aveson V, Massa AL, Zhang L, Torres D, Makohon-Moore AP, Lecomte N, et al: Pancreatic cancer prognosis is predicted by an ATAC-array technology for assessing chromatin accessibility. Nat Commun 12: 3044, 2021

54. Lamouille S, Xu J and Derynck R: Molecular mechanisms of epithelial-mesenchymal transition. Nat Rev Mol Cell Biol 15: 178-196, 2014

55. Sannino G, Armbruster N, Bodenhöfer M, Haerle U, Behrens D Buchholz M, Rothbauer U, Sipos B and Schmees C: Role of BCL9L in transforming growth factor- $\beta$ (TGF- $\beta$ )-induced epithelial-to-mesenchymal-transition (EMT) and metastasis of pancreatic cancer. Oncotarget 7: 73725-73738, 2016.

56. Ye X and Weinberg RA: Epithelial-mesenchymal plasticity: A central regulator of cancer progression. Trends Cell Biol 25: 675-686, 2015

57. Oberstein PE and Olive KP: Pancreatic cancer: Why is it so hard to treat? Therap Adv Gastroenterol 6: 321-337, 2013

58. Grivennikov SI, Greten FR and Karin M: Immunity, inflammation, and cancer. Cell 140: 883-899, 2010

59. Carbone $\mathrm{C}$ and Melisi D: NF- $\kappa \mathrm{B}$ as a target for pancreatic cancer therapy. Expert Opin Ther Targets 16 (Suppl 2): S1-S10, 2012.

60. Pires BR, Mencalha AL, Ferreira GM, de Souza WF Morgado-Díaz JA, Maia AM, Corrêa S and Abdelhay ES NF-kappaB is involved in the regulation of EMT genes in breast cancer cells. PLoS One 12: e0169622, 2017.

61. Labelle M, Begum S and Hynes RO: Direct signaling between platelets and cancer cells induces an epithelial-mesenchymal-like transition and promotes metastasis. Cancer Cell 20: 576-590, 2011

62. Buscail L, Bournet B and Cordelier P: Role of oncogenic KRAS in the diagnosis, prognosis and treatment of pancreatic cancer. Nat Rev Gastroenrerol Hepatol 17: 153-168, 2020.

63. Yang J, Li S, Li J, Wang F, Chen K, Zheng Y, Wang J, Lu W, Zhou Y, Yin Q, et al: A meta-analysis of the diagnostic value of detecting K-ras mutation in pancreatic juice as a molecula marker for pancreatic cancer. Pancreatology 16: 605-614, 2016.

64. Dong L, Wang S, Fu B and Wang J: Evaluation of droplet digital PCR and next generation sequencing for characterizing DNA reference material for KRAS mutation detection. Sci Rep 8: 9650, 2018.

65. Patel SA and Vanharanta S: Epigenetic determinants of metastasis. Mol Oncol 11: 79-96, 2017.
66. Thålin C, Hisada Y, Lundström S, Mackman N and Wallén H: Neutrophil extracellular traps: Villains and targets in arterial, venous, and cancer-associated thrombosis. Arterioscler Thromb Vasc Biol 39: 1724-1738, 2019.

67. Pastushenko I, Brisebarre A, Sifrim A, Fioramonti M, Revenco T, Boumahdi S, Van Keymeulen A, Brown D, Moers V, Lemaire $\mathrm{S}$, et al: Identification of the tumour transition states occurring during EMT. Nature 556: 463-468, 2018.

68. Murthy P, Singhi AD, Ross MA, Loughran P, Paragomi P, Papachristou GI, Whitcomb DC, Zureikat AH, Lotze MT, Zeh Iii HJ and Boone BA: Enhanced neutrophil extracellular trap formation in acute pancreatitis contributes to disease severity and is reduced by chloroquine. Front Immunol 10: 28, 2019.

69. Kajioka H, Kagawa S, Ito A, Yoshimoto M, Sakamoto S, Kikuchi S, Kuroda S, Yoshida R, Umeda Y, Noma K, et al: Targeting neutrophil extracellular traps with thrombomodulin prevents pancreatic cancer metastasis. Cancer Let 497: 1-13, 2021.

70. Zhang K, Sun X, Zhou X, Han L, Chen L, Shi Z, Zhang A, Ye M, Wang Q, Liu C, et al: Long non-coding RNA HOTAIR promotes glioblastoma cell cycle progression in an EZH2 dependent manner Oncotarget 6: 537-546 2015.

71. Jiao F, Hu H, Han T, Yuan C, Wang L, Jin Z, Guo Z and Wang L: Long noncoding RNA MALAT-1 enhances stem cell-like phenotypes in pancreatic cancer cells. Int J Mol Sci 16: 6677-6693, 2015.

72. Sun YW, Chen YF, Li J, Huo YM, Liu DJ, Hua R, Zhang JF, Liu W, Yang JY, Fu XL, et al: A novel long non-coding RNA ENST00000480739 suppresses tumour cell invasion by regulating OS-9 and HIF-1alpha in pancreatic ductal adenocarcinoma. Br J Cancer 111: 2131-2141, 2014

73. Ye Y, Chen J, Zhou Y, Fu Z, Zhou Q, Wang Y, Gao W, Zheng S, Zhao X, Chen T and Chen R: High expression of AFAP1-AS1 is associated with poor survival and short-term recurrence in pancreatic ductal adenocarcinoma. J Transl Med 13: 137, 2015.

74. Huang X, Zhi X, Gao Y, Ta N, Jiang $H$ and Zheng J: LncRNAs in pancreatic cancer. Oncotarget 7: 57379-57390, 2016

75. Wang Y, Jiang XM, Feng ZX, Li XL and Zhang WL: Long noncoding RNA PCAT-1 accelerates the metastasis of pancreatic cancer by repressing RBM5. Eur Rev Med Pharmacol Sci 23: 7350-7355, 2019

76. Marrelli D, Caruso S, Pedrazzani C, Neri A, Fernandes E, Marini M, Pinto E and Roviello F: CA19-9 serum levels in obstructive jaundice: Clinical value in benign and malignant conditions. Am J Surg 198: 333-339, 2009

77. Shang X, Song C, Du X, Shao H, Xu D and Wang X: The serum levels of tumor marker CA19-9, CEA, CA72-4, and NSE in type 2 diabetes without malignancy and the relations to the metabolic control. Saudi Med J 38: 204-208, 2017.

78. Yoshida H, Onda M, Tajiri T, Mamada Y, Taniai N, Mineta S, Hirakata A, Futami R, Arima Y, Inoue M, et al: Infected hepatic cyst. Hepatogastroenterology 50: 507-509, 2003.

79. Zhai H, Huang J, Yang C, Fu Y and Yang B: Serum CEA and CA19-9 levels are associated with the presence and severity of colorectal neoplasia. Clin Lab 64: 351-356, 2018.

80. Ballehaninna UK and Chamberlain RS: The clinical utility of serum CA 19-9 in the diagnosis, prognosis and management of pancreatic adenocarcinoma: An evidence based appraisal. J Gastrointest Oncol 3: 105-119, 2012.

81. Tempero MA, Arnoletti JP, Behrman S, Ben-Josef E, Benson AB III, Berlin JD, Cameron JL, Casper ES, Cohen SJ, Duff M, et al: Pancreatic adenocarcinoma. J Natl Compr Canc Netw 8: 972-1017, 2010.

82. Kimmey MB, Bronner MP, Byrd DR and Brentnall TA: Screening and surveillance for hereditary pancreatic cancer. Gastrointest Endosc 56 (Suppl 4): S82-S86, 2002.

83. Goggins M, Overbeek KA, Brand R, Syngal S, Del Chiaro M, Bartsch DK, Bassi C, Carrato A, Farrell J, Fishman EK, et al: Management of patients with increased risk for familial pancreatic cancer: Updated recommendations from the International Cancer of the Pancreas Screening (CAPS) Consortium. Gut 69: 7-17, 2020.

84. Ben Q, Xu M, Ning X, Liu J, Hong S, Huang W, Zhang H and Li Z: Diabetes mellitus and risk of pancreatic cancer: A meta-analysis of cohort studies. Eur J Cancer 47: 1928-1937, 2011.

85. Kirkegård J, Mortensen FV and Cronin-Fenton D: Chronic pancreatitis and pancreatic cancer risk: A systematic review and Meta-analysis. Am J Gastroenterol 112: 1366-1372, 2017.

86. Gaiser RA, Halimi A, Alkharaan H, Lu L, Davanian H, Healy K, Hugerth LW, Ateeb Z, Valente R, Fernández Moro C, et al: Enrichment of oral microbiota in early cystic precursors to invasive pancreatic cance. Gut 68: 2186-2194, 2019. 
87. Duraker N, Hot S, Polat Y, Höbek A, Gencler N and Urhan N CEA, CA 19-9, and CA 125 in the differential diagnosis of benign and malignant pancreatic diseases with or without jaundice. J Surg Oncol 95: 142-147, 2007.

88. Rieser CJ, Zenati M, Hamad A, Al Abbas AI, Bahary N, Zureikat AH, Zeh HJ III and Hogg ME: CA19-9 on postoperative surveillance in pancreatic ductal adenocarcinoma: Predicting recurrence and changing prognosis over time. Ann Surg Oncol 25: 3483-3491, 2018.

89. Azizian A, Rühlmann F, Krause T, Bernhardt M, Jo P, König A, Kleiß M, Leha A, Ghadimi M and Gaedcke J: CA19-9 for detecting recurrence of pancreatic cancer. Sci Rep 10: 1332, 2020.

90. Ferrone CR, Finkelstein DM, Thayer SP, Muzikansky A, Fernandez-delCastillo C and Warshaw AL: Perioperative CA19-9 levels can predict stage and survival in patients with resectable pancreatic adenocarcinoma. J Clin Oncol 24: 2897-2902, 2006.

91. Berger AC, Garcia M Jr, Hoffman JP, Regine WF, Abrams RA Safran H, Konski A, Benson AB III, MacDonald J and Willett CG: Postresection CA 19-9 predicts overall survival in patients with pancreatic cancer treated with adjuvant chemoradiation: A prospective validation by RTOG 9704. J Clin Oncol 26: 5918-5922, 2008

92.Jia F, Liu M, Li X, Zhang F, Yue S and Liu J: Relationship between S100A4 protein expression and pre-operative serum CA19.9 levels in pancreatic carcinoma and its prognostic significance. World J Surg Oncol 17: 163, 2019.

93. Moro L,Simoneschi D, KurzE, Arbini AA,Jang S, Guaragnella N, Giannattasio S, Wang W, Chen YA, Pires G, et al: Epigenetic silencing of the ubiquitin ligase subunit FBXL7 impairs c-SRC degradation and promotes epithelial-to-mesenchymal transition and metastasis. Nat Cell Biol 22: 1130-1142, 2020.

94. Moro L and Pagano M: Epigenetic suppression of FBXL7 promotes metastasis. Mol Cell Oncol 7: 1833698, 2020

95. Baumert M, Surmiak P, Szymkowiak M and Janosz A: The assessment of Pentraxin 3: A novel biomarker in early detection of infection in newborns. Biomed Res Int 2021: 6638622, 2021.

96. Goulart MR, Watt J, Siddiqui I, Lawlor RT, Imrali A, Hughes C, Saad A, ChinAleong J, Hurt C, Cox C, et al: Pentraxin 3 is a stromally-derived biomarker for detection of pancreatic ductal adenocarcinoma. NPJ Precis Oncol 5: 61, 2021.

97. Laklai H, Miroshnikova YA, Pickup MW, Collisson EA, Kim GE, Barrett AS, Hill RC, Lakins JN, Schlaepfer DD, Mouw JK, et al: Genotype tunes pancreatic ductal adenocarcinoma tissue tension to induce matricellular fibrosis and tumor progression. Nat Med 22: 497-505, 2016.

98. Vennin C, Murphy KJ, Morton JP, Cox TR, Pajic M and Timpson P: Reshaping the tumor stroma for treatment of pancreatic cancer. Gastroenterology 154: 820-838, 2018.

99. Kim EJ, Sahai V, Abel EV, Griffith KA, Greenson JK, Takebe N, Khan GN, Blau JL, Craig R, Balis UG, et al: Pilot clinical trial of hedgehog pathway inhibitor GDC-0449 (vismodegib) in combination with gemcitabine in patients with metastatic pancreatic adenocarcinoma. Clin Cancer Res 20: 5937-5945, 2014.

100. Catenacci DV, Junttila MR, Karrison T, Bahary N, Horiba MN, Nattam SR, Marsh R, Wallace J, Kozloff M, Rajdev L, et al: Randomized Phase Ib/II study of gemcitabine plus placebo or vismodegib, a hedgehog pathway inhibitor, in patients with metastatic pancreatic cancer. J Clin Oncol 33: 4284-4292, 2015.

101. Ko AH, LoConte N, Tempero MA, Walker EJ, Kate Kelley R, Lewis S, Chang WC, Kantoff E, VannierMW, Catenacci DV, et al: A phase I study of FOLFIRINOX Plus IPI-926, a hedgehog pathway inhibitor, for advanced pancreatic adenocarcinoma. Pancreas 45: 370-375, 2016.

102. Ramanathan RK, McDonough S, Philip PA, Hingorani SR, Lacy J, Kortmansky JS, Thumar J, Chiorean EG, Shields AF, Behl D, et al: Phase IB/II randomized study of FOLFIRINOX plus pegylated recombinant human hyaluronidase versus FOLFIRINOX alone in patients with metastatic pancreatic adenocarcinoma: SWOG S1313. J Clin Oncol 37: 1062-1069, 2019.

103. Wang WQ, Liu L, Xu JZ and Yu XJ: Reflections on depletion of tumor stroma in pancreatic cancer. Biochim Biophys Acta Rev Cancer 1871: 267-272, 2019.

104. Özdemir BC, Pentcheva-Hoang T, Carstens JL, Zheng X, Wu CC, Simpson TR, Laklai H, Sugimoto H, Kahlert C, Novitskiy SV, et al: Depletion of carcinoma-associated fibroblasts and fibrosis induces immunosuppression and accelerates pancreas cancer with reduced survival. Cancer Cell 28: 831-833, 2015.

105. Lee JJ, Perera RM, Wang H, Wu DC, Liu XS, Han S, Fitamant J, Jones PD, Ghanta KS, Kawano S, et al: Stromal response to Hedgehog signaling restrains pancreatic cancer progression. Proc Natl Acad Sci USA 111: E3091-E3100, 2014.
106. Roberts KJ, Kershner AM and Beachy PA: The stromal niche for epithelial stem cells: A template for regeneration and a brake on malignancy. Cancer Cell 32: 404-410, 2017

107. Lin Z, Lu S, Xie X, Yi X and Huang H: Noncoding RNAs in drug-resistant pancreatic cancer: A review. Biomed Pharmacother 131: 110768, 2020.

108. Peng Y and Croce CM: The role of MicroRNAs in human cancer. Signal Transduct Target Ther 1: 15004, 2016.

109. Lee YS and Dutta A: MicroRNAs in cancer. Annu Rev Pathol 4 : 199-227, 2009

110. Khan IA, Rashid S, Singh N, Rashid S, Singh V, Gunjan D, Das P, Dash NR, Pandey RM, Chauhan SS, et al: Panel of serum miRNAs as potential non-invasive biomarkers for pancreatic ductal adenocarcinoma. Sci Rep 11: 2824, 2021.

111. Greither T, Grochola LF, Udelnow A, Lautenschlager C, Wurl P and Taubert H: Elevated expression of microRNAs 155, 203, 210 and 222 in pancreatic tumors is associated with poorer survival. Int J Cancer 126: 73-80, 2010.

112. Schultz NA, Andersen KK, Roslind A, Willenbrock H, Wojdemann M and Johansen JS: Prognostic microRNAs in cancer tissue from patients operated for pancreatic cancer-five microRNAs in a prognostic index. World J Surg 36: 2699-2707, 2012.

113. Ye ZQ, Zou CL, Chen HB, Jiang MJ, Mei Z and Gu DN: MicroRNA-7 as a potential biomarker for prognosis in pancreatic cancer. Dis Markers 2020: 2782101, 2020.

114. Kumarswamy R, Volkmann I and Thum T: Regulation and function of miRNA-21 in health and disease. RNA Biol 8: 706-713, 2011.

115. Liu R, Zhang H, Wang X, Zhou L, Li H, Deng T, Qu Y, Duan J, Bai M, Ge S, et al: The miR-24-Bim pathway promotes tumor growth and angiogenesis in pancreatic carcinoma. Oncotarget 6: 43831-43842, 2015

116. Zhang L, Jamaluddin MS, Weakley SM, Yao Q and Chen C: Roles and mechanisms of microRNAs in pancreatic cancer. World J Surg 35: 1725-1731, 2011

117. Habbe N, Koorstra JB, Mendell JT, Offerhaus GJ, Ryu JK, Feldmann G, Mullendore ME, Goggins MG, Hong SM and Maitra A: MicroRNA miR-155 is a biomarker of early pancreatic neoplasia. Cancer Biol Ther 8: 340-346, 2009.

118. Huang X, Ding L, Bennewith KL, Tong RT, Welford SM, Ang KK, Story M, Le QT and Giaccia AJ: Hypoxia-inducible mir-210 regulates normoxic gene expression involved in tumor initiation. Mol Cell 35: 856-867, 2009.

119. Wu X, Wang Y, Yu T, Nie E, Hu Q, Wu W, Zhi T, Jiang K, Wang X, Lu X, et al: Blocking MIR155HG/miR-155 axis inhibits mesenchymal transition in glioma. Neurooncology 19: 1195-1205, 2017

120. Korpal M, Lee ES, Hu G and Kang Y: The miR-200 family inhibits epithelial-mesenchymal transition and cancer cell migration by direct targeting of E-cadherin transcriptional repressors ZEB1 and ZEB2. J Biol Chem 283: 14910-14914, 2008

121. Luthra R, Singh RR, Luthra MG, Li YX, Hannah C, Romans AM, Barkoh BA, Chen SS, Ensor J, Maru DM, et al: MicroRNA-196a targets annexin A1: A microRNA-mediated mechanism of annexin A1 downregulation in cancers. Oncogene 27: 6667-6678, 2008.

122. Ma Y, Yu S, Zhao W, Lu Z and Chen J: miR-27a regulates the growth, colony formation and migration of pancreatic cancer cells by targeting Sprouty2. Cancer Lett 298: 150-158, 2010.

123. Du J, Zheng X, Cai S, Zhu Z, Tan J, Hu B, Huang Z and Jiao H: MicroRNA-506 participates in pancreatic cancer pathogenesis by targeting PIM3. Mol Med Rep 12: 5121-5126, 2015.

124. Chen Z, Chen LY, Dai HY, Wang P, Gao S and Wang K: miR-301a promotes pancreatic cancer cell proliferation by directly inhibiting Bim expression. J Cell Biochem 113: 3229-3235, 2012.

125. Fu Y, Liu X, Chen Q, Liu T, Lu C, Yu J, Miao Y and Wei J: Downregulated miR-98-5p promotes PDAC proliferation and metastasis by reversely regulating MAP4K4. J Exp Clin Cancer Res 37: 130, 2018

126. Chang W, Liu M, Xu J, Fu H, Zhou B, Yuan T and Chen P. MiR-377 inhibits the proliferation of pancreatic cancer by targeting Pim-3. Tumour Biol 37: 14813-14824, 2016.

127. Fu XF, Zhao HC, Yang CL, Chen CZ, Wang K, Gao F, Tian YZ and Zhao HL: MicroRNA-203-3p inhibits the proliferation, invasion and migration of pancreatic cancer cells by downregulating fibroblast growth factor 2. Oncol Lett 22: 626, 2021.

128. Liu G,Ji L, Ke M, Ou Z, Tang N and Li Y: miR-125a-3p is responsible for chemosensitivity in PDAC by inhibiting epithelial-mesenchymal transition via Fyn. Biomed Pharmacother 106: 523-531, 2018.

This work is licensed under a Creative Commons

Attribution-NonCommercial-NoDerivatives 4.0 International (CC BY-NC-ND 4.0) License. 